\title{
Projeto de letramento e sequência didática na OLP: propostas para o ensino de leitura e escrita
}

Literacy project and teaching sequence in OLP: proposals for

Francisca Vaneíse Andrade FERNANDES (UFRN) vaneisefernandes@edu.ufrn.br Priscila do Vale Silva MEDEIROS (UERN) priscilavale@uern.br

Recebido em: 30 de jan. de 2019. Aceito em: 12 de jun. de 2019 .

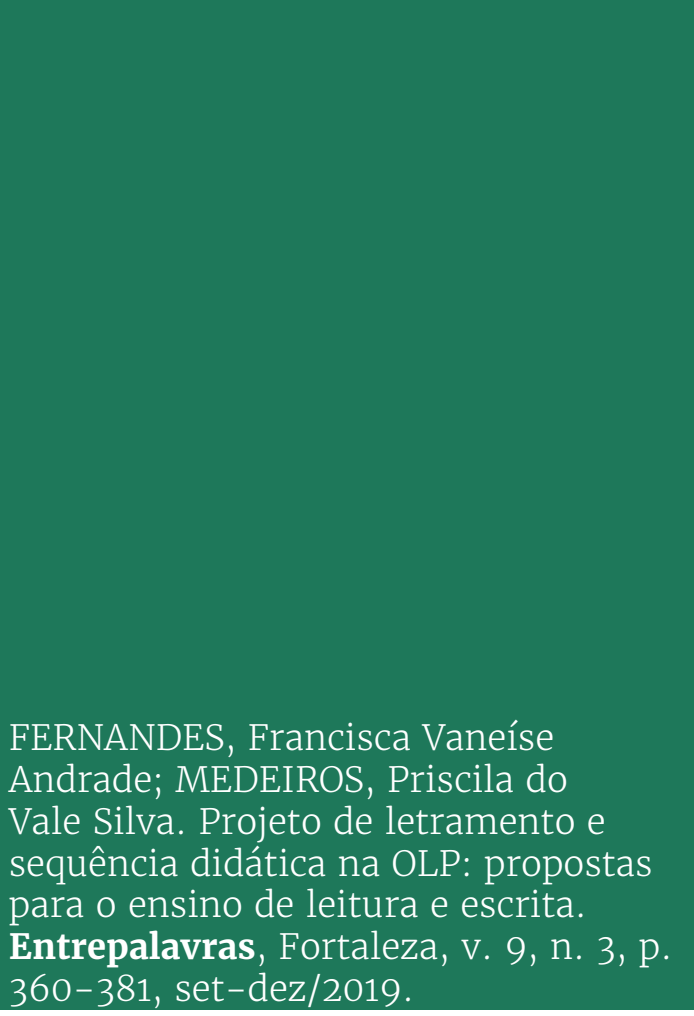

Resumo: Neste artigo, pretendemos evidenciar as contribuições decorrentes de dois modelos didáticos: um projeto de letramento e uma sequência didática, ambos voltados para o ensino de leitura e escrita. Teoricamente, fundamentamonos nos estudos de letramento (KLEIMAN, 2000, 2006; TINOCO, 2008; OLIVEIRA; TINOCO; SANTOS, 2011) e no modelo de sequência didática (DOLZ; SCHNEUWLY, 2004; ARAÚJO, 2013). Metodologicamente, este trabalho está ancorado na Linguística Aplicada (MOITA LOPES, 2006) e, para a análise que ora nos propomos, investimos em um trabalho interpretativista dos corpora de duas pesquisas de intervenção desenvolvidas no âmbito do Mestrado Profissional em Letras (PROFLETRAS) e que tiveram em comum a participação na Olimpíada de Língua Portuguesa. A análise desses dados evidencia três contribuições que emergem do projeto de letramento e da sequência didática focalizados e que são comuns às duas propostas de ensino de leitura e escrita: escrita como prática social, produção de diferentes gêneros e ressignificação da prática de alunos e professores.

Palavras-chave: Projeto de letramento. Sequência didática. Ensino de leitura e escrita. Escrita como prática social. 
Abstract: This paper aims to stress about the contributions resulted from two educational models: a literacy project and a teaching sequence, both focusing on the reading and writing education. For this purpose, Kleiman (2000, 2006) Tinoco (2008), Oliveira, Tinoco and Santos (2011) were used as theoretical background for the analysis regarding literacy studies and Dolz and Schneuwly (2004) and Araújo (2013) for the analysis on teaching sequence model. This study used an approach based on Applied Linguistics (MOITA LOPES, 2006). Also, the analysis of two intervention studies developed in the Professional Master's Program (PROFLETRAS) - both having participated in the Portuguese Language Olympics - was performed. The results showed that three main aspects emerged from both literacy project and teaching sequence models under analysis: writing as a social practice, production of different genres and resignification of the practice of teachers and students.

Keywords: Literacy project. Teaching sequence. Reading and writing education. Writing as a social practice.

\section{Considerações iniciais}

A ressignificação do ensino de língua portuguesa tem sido foco de diversas políticas públicas para melhoria da educação, tais como a publicação dos Parâmetros Curriculares Nacionais (PCN), em 1997, da Base Nacional Comum Curricular (BNCC), em 2018, como também o lançamento da Olimpíada de Língua Portuguesa (OLP), em 2002, em rede nacional, que é um projeto com vistas ao fortalecimento do ensino de Língua Portuguesa. Além disso, houve a criação de um importante programa de formação de professores de Língua Portuguesa: o Mestrado Profissional em Letras (ProfLetras), com início em 2013, do qual emergiram projetos de intervenção realizados em escolas públicas de todo o Brasil.

O conjunto dessas ações aponta para uma mudança de perspectiva na formação dos professores e, consequentemente, no ensino-aprendizagem de leitura, escrita e oralidade. Em decorrência disso, atividades tradicionais com foco somente em classificação gramatical, ortografia, por exemplo, dão lugar a atividades em que o foco se volta para o ensino de gêneros textuais ou discursivos ${ }^{1}$ e para diferentes práticas sociais de uso da linguagem, a fim de que os alunos possam encontrar sentido no que leem e escrevem, e percebam que a leitura e a escrita têm uma função social.

\footnotetext{
${ }^{1}$ Por compreendermos que se trata de conceitos diferentes, assumimos, ao longo do texto, ora "gêneros textuais", com base nos pressupostos teóricos da Escola de Genebra, presentes nas Sequências Didáticas (DOLZ; SCHNEUWLY, 2004), ora "gêneros discursivos", na perspectiva dos Estudos de Letramento de vertente etnográfica, ancorados no conceito bakhtiniano de gêneros do discurso (BAKHTIN, 1992). Em relação às contribuições mapeadas neste trabalho, utilizamos "gêneros" para nos referirmos tanto a gêneros textuais quanto discursivos, uma vez que resultam de dados de duas pesquisas diferentes.
} 
V. 9 (3)

$360-381$

set-dez

2019

Nesse contexto, temos como objetivo evidenciar contribuições metodológicas decorrentes de dois modelos didáticos: um projeto de letramento e uma sequência didática. Para tanto, investimos em um trabalho interpretativista, por meio da análise de dados gerados em dois projetos de intervenção (FERNANDES, 2015; MEDEIROS, 2015) decorrentes do ProfLetras. Essas pesquisas tiveram como ponto de partida a participação em um concurso nacional de escrita: a Olimpíada de Língua Portuguesa. O trabalho de Fernandes (2015) focalizou o desenvolvimento da OLP por meio de um Projeto de Letramento (PL), proposto por Kleiman (2000), e o de Medeiros (2015) seguiu a perspectiva teórico-metodológica de Sequências Didáticas (SD), conforme proposto por Dolz e Schneuwly (2004).

As pesquisas foram realizadas com turmas de $7^{\circ}$ ano, em escolas públicas das cidades de Natal e Macau, ambas localizadas no estado do Rio Grande do Norte, sendo as professoras pesquisadoras participantes de diferentes turmas do ProfLetras (UFRN - Natal e UERN - Assu).

Do ponto de vista teórico, este trabalho fundamenta-se nos estudos de letramento, sobretudo no letramento de vertente etnográfica, que compreende a leitura e a escrita como práticas sociais (KLEIMAN, 2000; 2006; TINOCO, 2008; OLIVEIRA; TINOCO; SANTOS, 2011); e no modelo de sequência didática (DOLZ; SCHNEUWLY, 2004; ARAÚJO, 2013), entendido como um conjunto de ações desenvolvidas pelo professor com vistas ao ensino de um gênero textual.

No que concerne aos aspectos metodológicos, ancoramo-nos em pressupostos advindos da Linguística Aplicada (LA), uma vez que, de acordo com Moita Lopes (2006, p. 102), "[...] tem como objetivo fundamental a problematização da vida social, na intenção de compreender as práticas sociais nas quais a linguagem tem papel crucial". Em outras palavras, a LA focaliza questões relativas ao uso da linguagem, tais como práticas de leitura e escrita abordadas neste trabalho.

Além disso, realizamos uma análise interpretativista doscorpora de duas pesquisas de intervenção, ambas relacionadas à Olimpíada de Língua Portuguesa e desenvolvidas no âmbito do Mestrado Profissional em Letras (PROFLETRAS), bem como do material disponibilizado pela olimpíada (CLARA; ALTENFELDER; ALMEIDA, 2002), o qual constitui importante instrumento didático de apoio para professores.

O resultado deste trabalho, a partir do seu objetivo, pode proporcionar a professores do ensino básico conhecimento acerca de duas propostas didáticas para o ensino de leitura e escrita, contribuindo, dessa forma, com o ensino de língua portuguesa, o que constitui a relevância deste estudo. 


\section{Projeto de Letramento e Sequência Didática: aspectos conceituais e metodológicos}

A proposta de trabalho com Projetos de Letramento (PL) inserese na perspectiva dos estudos de letramento de vertente etnográfica, que compreende o letramento como os usos da língua escrita em diferentes esferas de atividade humana, uma vez que a escrita se faz presente em inúmeras práticas sociais por meio das quais os indivíduos interagem (KLEIMAN, 1995). Assim, o conceito de projeto de letramento compreende

[...] um conjunto de atividades que se origina de um interesse real na vida dos alunos e cuja realização envolve o uso da escrita, isto é, a leitura de textos que, de fato, circulam na sociedade e a produção de textos que serão lidos, em um trabalho coletivo de alunos e professor, cada um segundo sua capacidade. O projeto de letramento é uma prática social em que a escrita é utilizada para atingir algum outro fim, que vai além da mera aprendizagem da escrita (a aprendizagem dos aspectos formais apenas), transformando objetivos circulares como 'escrever para aprender a escrever' e 'ler para aprender a ler' em ler e escrever para compreender e aprender aquilo que for relevante para o desenvolvimento e a realização do projeto. (KLEIMAN, 2000, p. 238).

Desta forma, um Projeto de Letramento tem como objetivo a resolução de um problema da comunidade escolar por meio do uso da escrita, tendo como ponto de partida uma situação real vivenciada por professores e alunos. De acordo com essa proposta, cada participante colabora com o desenvolvimento do projeto de acordo com as suas possibilidades, o que implica propor atividades colaborativas e heterogêneas, visando ao sucesso coletivo, tendo em vista que os sujeitos não aprendem da mesma forma.

Além disso, conforme Tinoco (2008), do Projeto de Letramento decorre um modelo didático, uma vez que apresenta características recorrentes, conforme podemos observar no quadro 1, a seguir. 
v. 9 (3) $360-381$ set-dez 2019

Quadro 1- Características recorrentes nos projetos de letramento

\begin{tabular}{|l|l|}
\hline \multicolumn{2}{|c|}{ Projetos de letramento: demandas de leitura e escrita como prática social (foco) } \\
\hline $\begin{array}{l}\text { Interatividade } \\
\text { e dialogismo }\end{array}$ & $\begin{array}{l}\text { Trabalho coletivo em torno da leitura e da escrita com funções } \\
\text { sociais, distribuição de tarefas, diálogo, reflexão na ação e sobre a } \\
\text { ação. }\end{array}$ \\
\hline Situação social & $\begin{array}{l}\text { Planejamento aberto a imprevistos, ampliação de tempos e } \\
\text { espaços de aprendizagem, diversidade de agentes e de formas de } \\
\text { participação, multiplicidade de gêneros orais e escritos, variedade } \\
\text { de recursos e instrumentos, autenticidade de textos, diferentes } \\
\text { modos de ler, escrever e falar, experimentação de usos da } \\
\text { linguagem em função de eventos específicos e necessidades locais. }\end{array}$ \\
\hline Agência social & $\begin{array}{l}\text { Atividades de leitura e escrita que objetivam agir sobre o mundo, } \\
\text { definição de propósitos de comunicação e de estratégias de ação, } \\
\text { compartilhamento dos aspectos macrossociais e microlinguísticos } \\
\text { envolvidos na produção oral e escrita em função do que se quer } \\
\text { atingir. }\end{array}$ \\
\hline $\begin{array}{l}\text { Pluralidade } \\
\text { cultural }\end{array}$ & $\begin{array}{l}\text { Vinculação do conhecimento à experiência humana, inclusão } \\
\text { de temas da cultura local, (re)construção e compartilhamento } \\
\text { de saberes e fazeres, interdisciplinaridade e transversalidade, } \\
\text { professores, alunos e membros da comunidade vistos como } \\
\text { sujeitos de conhecimentos, construção de versões da história. }\end{array}$ \\
\hline 2008, p. 218).
\end{tabular}

No quadro 1, podemos visualizar quatro características que são recorrentes nos Projetos de Letramento: interatividade e dialogismo, situação social, agência social e pluralidade, aspectos fundantes para a estruturação desse tipo de projeto, uma vez que é, a partir da mobilização e articulação desses elementos, que o PL se constitui como tal e pode vir a possibilitar a ressignificação do ensino de língua portuguesa. No entanto, mesmo considerando tais elementos como basilares para o desenvolvimento de Projetos de Letramento, outros podem emergir de acordo com demandas de cada projeto, tendo em vista seu caráter situado.

Em relação ao aspecto da interatividade e dialogismo, no PL o foco recai sobre um trabalho colaborativo e reflexivo, em que as tarefas são compartilhadas objetivando alcançar um propósito comum definido pelo grupo. No que concerne à situação social, para a realização do PL é necessário considerar o aspecto situado do projeto, bem como um planejamento flexível, além de mudanças no tempo e espaço de aprendizagem, com ações que ultrapassam os muros escolares. A agência social, por sua vez, está relacionada ao uso efetivo da escrita, com vistas à ação social, por meio de gêneros discursivos utilizados com os mais diferentes propósitos comunicativos e por diversos agentes de letramento (KLEIMAN, 2006). Por fim, a pluralidade cultural diz 
respeito ao imbricamento com outras áreas do conhecimento de acordo com necessidades do projeto. Além disso, visa ao reconhecimento que os indivíduos podem vir a ter de si mesmos como sujeitos históricos, capazes, com sentimento de pertença em relação à comunidade, que possam valorizar a própria cultura.

A Sequência Didática (SD), por sua vez, na perspectiva do grupo de Genebra, tem-se apresentado como uma proposta para o ensino de gêneros, uma vez que, segundo Dolz; Schneuwly (2004, p. 82), Sequência Didática consiste em "[...] um conjunto de atividades escolares organizadas, de maneira sistemática, em torno de um gênero textual oral ou escrito". Em outras palavras, nesse "procedimento", como o nomeiam os autores, o gênero ocupa um lugar central, visto que a elaboração e a realização das atividades que fazem parte da SD estão voltadas para o ensino e a aprendizagem de um gênero.

Para esses autores, quando há, na escola, estímulo ao desenvolvimento de situações que promovam atividades voltadas para a escrita e a fala, há a possibilidade de os alunos aprenderem a escrever textos e a se expressarem oralmente, adequando-se às diversas situações comunicativas demandadas pelas interações sociais.

Araújo (2013, p. 322) afirma que "O modelo de sequência didática está associado às pesquisas sobre a aquisição da língua escrita através de um trabalho sistemático com gêneros textuais desenvolvidas pelo grupo de Genebra". Nessa perspectiva, a opção pelo desenvolvimento de sequências didáticas para o ensino de língua materna requer do professor a organização de um planejamento pautado em uma série de atividades em torno de um gênero, para que, por meio delas, os alunos possam se apropriar da escrita de textos e usá-los (ou não) em sua vida social.

Assim, o trabalho com sequência didática tem como objetivo principal propiciar aos alunos a aprendizagem de gêneros, sejam eles orais ou escritos. Nesse contexto, Medeiros (2015) defende que:

A construção de uma sequência didática parte da perspectiva de oportunizar experiências que se movimentam entre as mais complexas >menos complexas >mais complexas, ou seja, iniciase com a produção textual, que é uma atividade extremamente complexa, desenvolve-se com atividades para aquisição das competências necessárias ao aprimoramento da habilidade da escrita ou da oralidade e retorna para a produção textual como forma de fechamento e avaliação de todo o processo formativo (MEDEIROS, 2015, p.49). 
v. 9 (3) $360-381$ set-dez 2019

De acordo com a autora, as atividades de escrita, consideradas complexas, são complementadas pelas atividades intercaladas (módulos) na SD, o que corrobora a proposta de Sequência Didática apresentada por Dolz; Schneuwly (2004), que evidenciam uma estrutura básica para o desenvolvimento de uma SD, afirmando que ela é composta por quatro partes, conforme demonstra a figura 1.

Figura 1 - Esquema da Sequência Didática
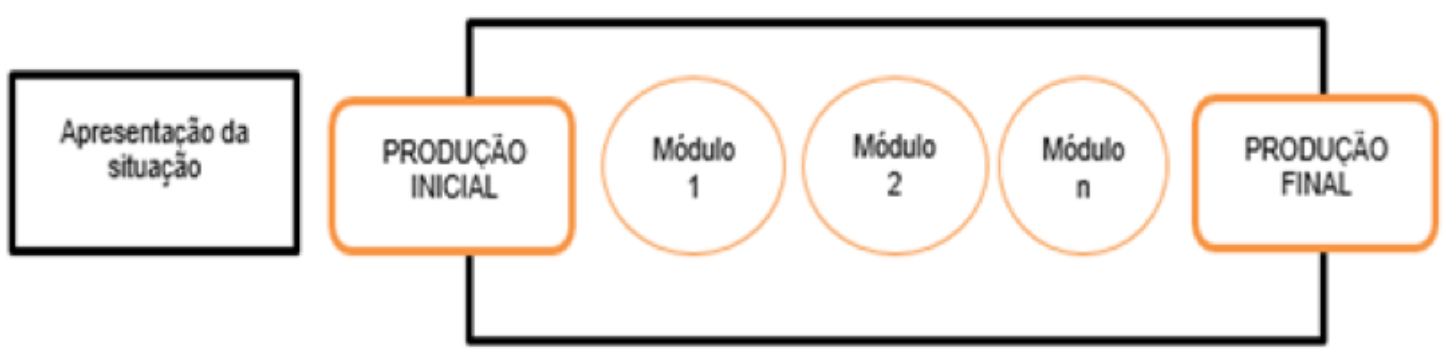

Fonte: Dolz e Schneuwly (2004, p. 83).

Na SD, o ponto de partida é a apresentação da situação, na qual há uma explicação detalhada sobre a tarefa a ser realizada, ou seja, sobre o gênero oral ou escrito que será produzido.

Em seguida, é a vez da produção inicial, isto é, o momento de produzir uma primeira versão do gênero a ser trabalhado. Nessa etapa da sequência, o professor pode observar os conhecimentos que os alunos já possuem sobre o gênero em estudo e adequar as próximas atividades da sequência de acordo com as dificuldades identificadas.

Os módulos, por sua vez, são atividades que focalizam o ensino do gênero de forma sistemática e aprofundada, partindo das dificuldades apresentadas pelos alunos na produção inicial e considerando elementos necessários à apropriação do gênero, tais como: estrutura, linguagem, função social, adequação ao leitor e ao suporte, aspectos linguístico-textuais.

A última etapa da sequência didática é a produção final. É nesse momento em que o aluno põe em prática os conhecimentos construídos ao longo da sequência didática.

\section{Olimpíada de Língua Portuguesa: o trabalho na perspectiva do Projeto de Letramento e da Sequência Didática}

A Olimpíada de Língua Portuguesa (OLP) é um programa de formação de professores, fruto de uma parceria público-privada entre o Ministério da Educação (MEC) e da Fundação Itaú Social, coordenado 
pelo Centro de Estudos e Pesquisas em Educação, Cultura e Ação Comunitária (CENPEC). Tendo como objetivo contribuir para avanços na escrita de alunos de escolas públicas, o programa, criado em 2002, promove um concurso de escrita que ocorre a cada dois anos e atende atualmente a alunos da educação básica pública, do $5^{\circ}$ ano do ensino fundamental ao $3^{\circ}$ ano do ensino médio.

Para o desenvolvimento do planejamento de atividades, os professores podem fazer uso de um material didático enviado às escolas participantes, o qual é composto por cadernos do professor contendo sequências didáticas para estudo de um gênero, CDs e coletâneas de textos específicos de cada gênero.

Neste trabalho, temos como referência a $4^{\mathrm{a}}$ edição, ocorrida em 2014, ano em que os dados foram gerados. Naquela edição, os gêneros determinados pela olimpíada foram: poema ( $5^{\circ}$ e $6^{\circ}$ anos); memórias literárias ( $7^{\circ}$ e $8^{\circ}$ anos); crônica ( $9^{\circ}$ ano do ensino fundamental e $1^{\circ}$ ano do ensino médio); artigo de opinião ( $2^{\circ}$ e $3^{\circ}$ anos do ensino médio), e o tema do concurso, desde a fundação do programa, em 2002, é O lugar onde vivo.

Assim, dois projetos de intervenção foram desenvolvidos no ano de 2014, em turmas de $7^{\circ}$ ano do ensino fundamental de duas escolas públicas do Rio Grande do Norte, por meio de uma Sequência Didática (MEDEIROS, 2015) e de um Projeto de Letramento (FERNANDES, 2015). Convém esclarecer que a OLP é realizada, em geral, por meio de Sequências Didáticas, mas, no desenvolvimento do projeto de intervenção mencionado, Fernandes (2015) a realizou por meio de um Projeto de Letramento, alterando, assim, a proposta inicial da OLP.

Os alunos participantes dos projetos de intervenção, junto com as professoras pesquisadoras, desenvolveram diversas atividades, seja em uma SD ou em um PL, a fim de escreverem as histórias de pessoas mais idosas das comunidades envolvidas nos projetos, com vistas a produzir memórias literárias para participar do concurso e para ressignificar o ensino de leitura e escrita. No entanto, mesmo tendo em comum a proposta da OLP relativa ao gênero a ser escrito e ao tema do concurso, os modelos didáticos dessas pesquisas ancoram-se em orientações teórico-metodológicas distintas.

Do projeto de intervenção de Fernandes (2015), decorreu o Projeto de Letramento "Em cada memória, um pedaço da história", cujo ponto de partida foi a resolução de um problema dos alunos e da professora: participar de um concurso nacional de escrita, a OLP. 
v. 9 (3)

$360-381$

set-dez

2019

Nesse caso, por se tratar de um Projeto de Letramento, a proposta metodológica para a escrita dos textos enviados para o concurso se dá de forma diferente do que geralmente propõe a olimpíada. Isso ocorre devido a modificações feitas no planejamento do professor, que opta por elaborar muitas das atividades realizadas de acordo com a necessidade do projeto à medida que vai se desenvolvendo. Então, mesmo se decidir realizar algumas oficinas disponibilizadas no Caderno do Professor, contido no material da olimpíada, o professor que desenvolve um PL não segue na íntegra o modelo proposto pela SD da OLP, uma vez que nesse tipo de projeto se lê e escreve para responder a demandas que emergem de práticas sociais de linguagem.

Em outras palavras, o foco está na resolução de problemas apontados pelos alunos, professores ou outros participantes da comunidade escolar, que atuam colaborativamente por meio da escrita na busca por soluções. Como consequência, uma rede de atividades e de gêneros discursivos é produzida, não somente um gênero. Por esse motivo, diversos gêneros orais, escritos e multimodais são produzidos com foco na prática social. A aprendizagem do gênero não é, então, o ponto de partida e de chegada, mas um meio para a realização de um objetivo comum do grupo envolvido no projeto.

A Sequência Didática desenvolvida por Medeiros (2015), por sua vez, partiu da proposta contida no material disponibilizado pela organização da OLP, mais especificamente do Caderno do Professor, com o título "Se bem me lembro...", que apresenta um conjunto de atividades para auxiliar o ensino-aprendizagem da escrita do gênero memórias literárias, destinado a alunos do $7^{\circ}$ ano do ensino fundamental.

Ao todo, são propostas 16 oficinas que seguem a estrutura da SD defendida pela escola de Genebra (DOLZ; SCHNEUWLY, 2004), voltada para uma metodologia de escrita que parte do conhecimento prévio do aluno para, a partir de então, iniciar estratégias de ensino do gênero, por meio de módulos (ou oficinas, conforme o material da OLP).

Para desenvolver a SD proposta pela OLP, as três primeiras oficinas sugerem ao professor atividades de contato inicial com o gênero memórias literárias, a partir de leitura de textos de memórias, produção de cartazes e murais com fotos antigas, apresentação de objetos disponibilizados por parentes ou amigos que possam remeter ao passado, além da organização de um plano de trabalho, feito de forma conjunta (alunos e professor). 
A partir da oficina 4, os alunos iniciam o processo de escrita da primeira versão do texto de memórias, que servirá de diagnóstico ao professor, a fim de subsidiá-lo no planejamento das atividades futuras para o ensino da escrita do gênero.

As oficinas seguintes, propostas pelo Caderno do Professor, orientam um trabalho voltado para a compreensão da dimensão global do texto, focalizando características da descrição em textos de memórias, comparações entre tempos passados e atuais, marcas linguísticas que contribuem para a progressão textual, entre outros aspectos.

O papel fundamental do professor nesse processo é o de, além de poder lançar mão das atividades já apresentadas no material da OLP, planejar ações a partir dos textos dos alunos, considerando as suas dificuldades de escrita do gênero proposto.

Concluídos os módulos (oficinas) destinados ao ensino da escrita do gênero, o professor propõe que uma segunda versão do texto seja escrita, agora contando com que os alunos tenham apreendido aspectos relativos à composição do gênero, além da adequação ao tema da OLP, que é O lugar onde vivo. Os ajustes finais são realizados na última oficina. Nesse momento, professor e alunos verificam se o texto produzido atende aos critérios da OLP, conforme disponibilizado no Caderno do Professor que, de uma forma geral, visam a identificar a adequação ao tema, ao gênero, as marcas de autoria e as convenções da escrita.

No trabalho com a SD, é relevante ressaltar que a proposta disponibilizada pela OLP deve servir como material de apoio ao professor, mas não precisa ser o único, tendo em vista que, mesmo sendo enviado para escolas públicas de todo o Brasil, a exemplo dos livros do Programa Nacional do Livro Didático (PNLD), as escolas e os sujeitos, seres históricos, variam de região para região. Sendo assim, fazendo uso da proposta da SD da OLP tão somente, o professor pode não conseguir atingir os objetivos propostos relativos à escrita de gêneros, conforme afirmam Fernandes (2015) e Medeiros (2015).

\section{Contribuições do Projeto de Letramento e da Sequência Didática para o ensino de leitura e escrita}

A partir da análise dos dados dos trabalhos de Fernandes (2015) e Medeiros (2015), foi possível observar contribuições para o ensino de leitura e escrita advindas do PL e da SD. Mesmo sendo, em 
v. 9 (3)

$360-381$

set-dez

2019

geral, diferentes quanto ao percurso metodológico, as propostas dos dois modelos didáticos evidenciam aspectos que podem favorecer $\mathrm{o}$ ensino-aprendizagem de língua portuguesa.

Em relação ao Projeto de Letramento, uma de suas principais características é seu caráter situado, isto é, ele muda conforme o lugar em que é desenvolvido, o tempo histórico e os sujeitos envolvidos no projeto. Assim, cada PL é diferente do outro, por isso não há uma sequência fixa de atividades e gêneros; o que há são aspectos recorrentes que estão presentes nos projetos dessa natureza, tais como: uma situação-problema como ponto de partida; gêneros discursivos não são preestabelecidos, mas emergem das necessidades do projeto; desenvolvimento de uma rede de atividades; foco na prática social de linguagem; redefinição do tempo e espaço escolares; criação de comunidades de aprendizagem; reposicionamento identitário de professores e alunos, entre outros aspectos. Logo, ainda que um mesmo PL seja realizado em turmas ou escolas diferentes, os participantes, com histórias de vida diversas, já não serão os mesmos e, dessa forma, o projeto também não o será. Assim, mesmo havendo princípios comuns a todos os Projetos de Letramento, é possível que a cada novo projeto, novos aspectos sejam evidenciados.

Quanto à Sequência Didática da OLP, em geral, não se modifica, podendo ser aplicada uma mesma proposta em diversas escolas, de cidades e sujeitos diferentes. No entanto, o trabalho com as sequências em diferentes espaços de aprendizagem pode ser semelhante, mas também diverso, isso depende da capacidade do professor de flexibilizar seu planejamento e de refletir sobre avanços e insucessos dos alunos, moldando suas aulas de acordo com as necessidades e a realidade deles. Portanto, é fundamental que o professor que pretenda realizar esse tipo de proposta tenha sensibilidade e flexibilidade quanto aos conteúdos, às atividades, aos gêneros a serem produzidos, aos sujeitos envolvidos, entendendo que, apesar da SD ser o ponto de partida, ela não precisa ser engessada, rígida, imutável, estanque.

Tendo esse olhar humanizado, sensível às necessidades dos alunos, professores envolvidos no trabalho com PL e SD podem vislumbrar diversas contribuições para a aprendizagem de leitura e escrita, como as que veremos no quadro 2. 
Quadro 2 - Contribuições do PL e da SD para o ensino de leitura e escrita

\begin{tabular}{|l|l|l|}
\hline \multicolumn{1}{|c|}{$\begin{array}{c}\text { PRINCIPAIS } \\
\text { CONTRIBUIÇÕES }\end{array}$} & \multicolumn{1}{|c|}{$\begin{array}{c}\text { PROJETO DE } \\
\text { LETRAMENTO }\end{array}$} & \multicolumn{1}{c|}{ SEQUÊNCIA DIDÁTICA } \\
\hline Escrita como prática social & $\begin{array}{l}\text { Participação em concurso } \\
\text { de escrita } \\
\text { Entrevistas com pessoas } \\
\text { da comunidade } \\
\text { Exposição de objetos } \\
\text { antigos } \\
\text { Concurso interno na escola } \\
\text { Lançamento de livro }\end{array}$ & $\begin{array}{l}\text { Participação em concurso } \\
\text { de escrita } \\
\text { Entrevistas com pessoas } \\
\text { da comunidade } \\
\text { Exposição de objetos } \\
\text { antigos } \\
\text { Participação na Expotec }\end{array}$ \\
\hline $\begin{array}{l}\text { Ressignificação da prática } \\
\text { de alunos e professores }\end{array}$ & $\begin{array}{l}\text { Agência social/agente de } \\
\text { letramento }\end{array}$ & $\begin{array}{l}\text { Reposicionamento } \\
\text { identitário }\end{array}$ \\
\hline $\begin{array}{l}\text { Produção de diferentes } \\
\text { gêneros }\end{array}$ & $\begin{array}{l}\text { Convite para exposição } \\
\text { Cartazes } \\
\text { Carta de solicitação } \\
\text { Roteiro para entrevista } \\
\text { Entrevista } \\
\text { Memórias literárias } \\
\text { Livro de memórias literárias } \\
\text { (impresso e digital) }\end{array}$ & $\begin{array}{l}\text { Entrevista } \\
\text { Plano de Trabalho } \\
\text { Resumo } \\
\text { Memórias literárias }\end{array}$ \\
\hline
\end{tabular}

Fonte: Autoria propria.

O quadro 2 apresenta, de forma concisa, aspectos delineadores do trabalho com Projeto de Letramento e com Sequência Didática na OLP. Nele, há três contribuições que emergem do PL e da SD em análise e que são comuns às duas propostas de ensino de leitura e escrita: escrita como prática social, ressignificação da prática de alunos e professores, e produção de diferentes gêneros. Dessas contribuições, decorrem redes de atividades e de gêneros que ora se aproximam ora se distanciam, além de características que evidenciam mudanças nas posturas de professores e alunos envolvidos no PL e na SD que se diferenciam de propostas de ensino mais tradicionais.

A primeira contribuição decorrente do trabalho com SD e PL é a escrita como prática social. Consideramos esse ponto como fundamental no ensino-aprendizagem de leitura e escrita, seja no PL ou na SD, porque, no trabalho com linguagem, é crucial que os alunos compreendam a importância que a escrita tem como instrumento de empoderamento que lhes permite agir, seja para buscar direitos, convidar, reivindicar, comunicar-se, solicitar, atender a quaisquer outras demandas sociais.

Dessa forma, ao longo da OLP, os alunos escreveram diversos textos com uma função social, isto é, não apenas para que o professor leia e atribua uma nota ao texto, mas para de fato responder a uma demanda da sociedade, uma necessidade de comunicação real. 
v. 9 (3)

$360-381$

set-dez

2019

Sendo assim, tanto no PL quanto na SD desenvolvidos, foram realizadas diversas atividades para atender às demandas das propostas de trabalho dos dois modelos didáticos. Entre essas atividades, podemos considerar que algumas foram mais relevantes e merecem destaque. Além disso, três foram recorrentes nas duas propostas: participação em concurso de escrita, entrevistas com pessoas da comunidade e exposição de objetos antigos; e outras três foram diferentes: concurso interno na escola e lançamento de livro (impresso e digital), no caso do PL, e participação na Expotec, uma feira de ciências promovida pelo Instituto Federal de Educação, Ciência e Tecnologia do Rio Grande do Norte - IFRN, no caso da SD.

Isso ocorre porque, como dissemos anteriormente, o ponto de partida do PL e da SD foi o mesmo, bem como algumas atividades propostas pela OLP. No entanto, ao longo da olimpíada, as atividades se diferenciam, sobretudo em virtude da proposta metodológica de cada modelo didático. Para a realização dessas atividades, foi necessário produzir diversos textos que foram enviados a destinatários reais e tiveram outros interlocutores, além das professoras e dos alunos.

Em relação à escrita como prática social no desenvolvimento do PL, focalizamos um recorte de dados: participação em concurso de escrita, exposição de objetos antigos e entrevistas com pessoas da comunidade, que foram realizadas com base nas orientações da OLP; além de concurso interno na escola e lançamento de livro, que foram planejadas para o desenvolvimento do PL, mas não faziam parte das orientações do material da olimpíada.

Asituação-problemainicialqueimpulsionou odesenvolvimento do PL foi: "o que é necessário fazer para poder participar da OLP?". Esse questionamento, levantado pelos alunos e pela professora de Língua Portuguesa, foi o ponto de partida para se pensar em atividades a serem realizadas e textos a serem escritos para que se pudesse chegar a esse objetivo. Algumas oficinas da OLP foram então realizadas, a exemplo das primeiras entrevistas com pessoas da comunidade para podermos conhecer histórias que possibilitassem a escrita de memórias literárias, gênero discursivo necessário à participação dos alunos no concurso.

Com o intuito de divulgar histórias sobre o tema O lugar onde vivo, a partir das primeiras entrevistas, realizamos uma exposição de fotografias e objetos antigos dos entrevistados, bem como de cartazes com pesquisas feitas sobre os temas mencionados nas entrevistas. No entanto, essas entrevistas não propiciaram a escrita de textos do gênero memórias literárias, tendo em vista o tangenciamento presente nos 
textos. Isso pode ter ocorrido porque as perguntas para a entrevista disponibilizadas no material da OLP: 1) "O(a) senhor(a) se lembra de alguma passagem marcante da sua vida nesta cidade? Que fato é esse? Por que ele foi marcante?" e 2) "O(a) senhor(a) tem algum objeto ou foto que lembre essa passagem de sua vida?" (CLARA; ALTENFELDER; ALMEIDA, 2002, p. 26) podem levar os entrevistados a dar respostas de cunho pessoal, fazendo com que a entrevista tome um rumo diferente do pretendido. Devido a esse problema, foi necessário modificar o planejamento e adicionar outros materiais e atividades ao PL.

Esse evento foi relevante para o projeto, pois, mesmo não tendo resultado na primeira versão dos textos de memórias literárias, possibilitou o conhecimento sobre algumas pessoas que vieram a participar da segunda entrevista, a qual foi fundamental para o desenvolvimento do PL e a escrita dos textos de memórias literárias. Além disso, evidenciou a necessidade de dar um novo direcionamento ao PL, favorecendo um olhar reflexivo da professora sobre sua própria prática.

Tendo em vista que, com a realização das primeiras oficinas da OLP, não obtivemos o sucesso esperado com as entrevistas, mostrou-se necessário realizar outras, dessa vez seguindo o planejamento do PL. Para tanto, foram selecionadas pessoas que mencionaram, nas primeiras entrevistas, assuntos considerados mais interessantes pelos alunos e pela professora. Houve casos também de pessoas que foram entrevistadas pela primeira vez.

Por se constituir como uma prática social, a entrevista foi feita com pessoas da comunidade escolar e também com pessoas externas à escola. Para tornar possível esse momento, algumas etapas se fizeram necessárias: 1) pesquisa sobre os temas escolhidos para as entrevistas; 2) produção de um roteiro com perguntas orientadoras; 3) visita para realização da entrevista; 4) processo de retextualização da entrevista oral para a escrita.

Essa metodologia baseada em processos é constitutiva dos Projetos de Letramento, haja vista que não é somente o produto final, a última versão do gênero discursivo que interessa ao PL. Estão relacionadas a esse tipo de projeto as diversas práticas de leitura e escrita realizadas no processo de produção do gênero, bem como os diversos gêneros que são produzidos nesse tempo-espaço, pois eles evidenciam avanços e dificuldades dos alunos que precisam ser sanadas e se tornam, dessa forma, parte importante do planejamento do PL. É nesse processo também que são evidenciados os saberes de cada um, suas competências e habilidades, de forma que possamos, ao longo do projeto, identificar de que maneira cada aluno participante pode contribuir, uma vez que atividades coletivas 
v. 9 (3) $360-381$ set-dez 2019

são privilegiadas em detrimento às atividades individuais.

Para exemplificar como se dá a escrita como prática social no PL, focalizamos, no quadro 3, uma dessas entrevistas, cuja versão passou por alguns dos processos mencionados, e que tem como tema "A presença dos americanos em Natal na época da II Guerra Mundial".

Quadro 3 - Entrevista com pessoa mais velha da comunidade - Projeto de Letramento Idade do entrevistado: 87 anos.

Data da entrevista: $17 / 07 / 14$

1- O que o senhor achou mais interessante durante a Segunda Guerra Mundial?

Foram também os costumes que os americanos trouxeram, além dos produtos novos que encantaram os natalenses.

2- Por que o senhor decidiu estudar para ser piloto de avião?

Por influência do meu irmão.

3- O senhor lembra como as mulheres se vestiam no casamento?

Elas se vestiam de rosa.

4- O senhor lembra como era Natal durante a guerra? Por exemplo: as casas, os costumes, o comércio, as festas?

Natal antigamente só tinha 55 mil habitantes e naquele tempo não existia a Base Aérea Parnamirim Field que foi construída pelos americanos.

5- Qual a origem do nome Trampolim da Vitória?

Porque Natal foi usada como base para chegar à Europa mais rápido. 6 - Como as pessoas de Natal se sentiram com a presença dos americanos entre elas?

Foi uma novidade para eles, porque os americanos tinham culturas diferentes.

7- Por que os preços dos produtos aumentaram nessa época?

Porque o dinheiro dos americanos valia muito naquela época e isso influenciou o preço alto no comércio.

8- Quantas pessoas o senhor acha que morreram durante a $2^{\mathrm{a}}$ Guerra Mundial?

Aproximadamente 60 milhões.

9- Como era Natal antes e durante a guerra?

Natal era bem diferente antes da guerra, não havia tantas casas de festas, e também com a chegada de novos produtos e o aumento da prostituição. 10- Como os natalenses reagiram com a chegada de novos produtos, como o chiclete e a Coca-Cola?

Ficaram surpresos com a chegada de novos produtos, e surpresos em saber que foram os primeiros do Brasil a provar chiclete.

Fonte: Fernandes (2015). 
A entrevista do quadro 3 cumpre sua função social, uma vez que foi de fato realizada a fim de conhecer o entrevistado e de se aprender sobre a realidade da cidade de Natal antigamente, para construir uma memória sobre o lugar. O entrevistado dessa vez foi um agente externo à comunidade escolar que viveu em Natal/RN no período da Segunda Guerra Mundial, quando a cidade foi intensamente modificada pela presença de militares americanos que de lá partiam para a guerra.

A escolha dos alunos por esse entrevistado se deu devido ao interesse deles pela temática, o que lhes incentivou a pesquisar sobre o entrevistado antes da entrevista e a elaborar perguntas mais direcionadas do que as disponibilizadas no material da OLP. A partir disso, foi possível conhecer fatos sobre a cidade naquele período e produzir memórias literárias sobre o lugar onde vivem, tema do concurso, além de conhecerem melhor histórias da sua cidade, ajudando-os a construir, assim, também a sua história.

Por saberem que a entrevista realmente seria feita com uma pessoa que pretendiam conhecer e sobre assunto do seu interesse, e não apenas como uma prática estritamente escolar para aprendizagem do gênero entrevista, os alunos se mostraram mais interessados e a leitura e a escrita, por consequência, foram aprendidas e utilizadas de forma mais significativa.

Observamos, ainda, que os textos de memórias literárias produzidos a partir dessa entrevista mostraram-se mais ricos em detalhes apreendidos durante a entrevista pelos alunos. Além disso, houve ainda maiores avanços em relação a versões anteriores do texto, relacionados à autoria, informatividade, progressão discursiva e aspectos linguístico-textuais, o que revela um salto de qualidade tanto em questões discursivas quanto linguísticas (ver FERNANDES, 2015).

Há outros dois eventos de letramento ${ }^{2}$ em que a escrita se constituiu como prática social e que fizeram parte do Projeto de Letramento em análise: um concurso de escrita e desenho realizado na escola e o lançamento de um livro de memórias literárias.

O primeiro evento foi organizado a fim de valorizar as produções dos alunos e de estimular avanços em leitura e escrita. Na ocasião, foram selecionados dez textos de memórias literárias e dez desenhos que melhor resgatassem a história da cidade de Natal/RN. Para avaliar os textos e os desenhos e escolher os melhores entre os vários produzidos por alunos de quatro turmas de $7^{\circ}$ ano, foi criada

${ }^{2}$ Eventos de letramento são eventos em que a fala se organiza em torno da compreensão de livros e textos escritos (KLEIMAN, 2005). 
v. 9 (3)

$360-381$

set-dez

2019

uma comissão formada por professores de Língua Portuguesa, História e Artes da própria escola, mestrandos do ProfLetras, pais de alunos, equipe gestora e coordenadoras da escola. Todos os alunos ganhadores foram premiados com tablet, para o primeiro lugar, e materiais escolares, para os demais, tudo conseguido por meio de campanhas e bazares realizados pelas professoras envolvidas no projeto.

Os textos e desenhos compõem um livro intitulado "Em cada memória, um pedaço da história", produzido pelos alunos e pela professora pesquisadora, com ajuda de outros importantes agentes de letramento que foram fundamentais nas entrevistas, pois foram suas histórias que permitiram a produção dos textos de memórias literárias e das ilustrações do livro. O lançamento do livro, culminância do PL, evidencia o protagonismo discente ocorrido durante todo o projeto, em que alunos se transformaram em escritores e ilustradores. Além disso, produziram histórias e ilustrações com uma função social: participar de outro concurso, dessa vez interno, e de um livro ${ }^{3}$ impresso e digital que pode ser lido por qualquer pessoa, tendo, assim, muitos outros interlocutores além dos alunos e professores.

Já as atividades desenvolvidas na Sequência Didática tiveram como ponto de partida a produção de uma versão do gênero memórias literárias para que, segundo a proposta da OLP, os alunos pudessem demonstrar o quanto já sabiam/conheciam do gênero, e que a professora pudesse, a partir de então, planejar as futuras atividades para o aprimoramento da escrita do gênero.

Nessa perspectiva, partindo da proposta anual da escola, que era, naquele ano, a de trabalhar com o tema dos 90 anos de fundação da Escola Estadual Duque de Caxias, percebemos que esta seria uma oportunidade para que pudéssemos, além de trabalhar a escrita dos alunos, sobretudo do gênero memórias literárias, promover atividades que pudessem favorecer também o sentimento de pertencimento, de identificação com aquele local (no caso, com a história do Grupo Escolar Duque de Caxias, quando da sua fundação).

De acordo com as orientações metodológicas das SD da OLP, redirecionamos as atividades, seguindo a temática do Grupo Escolar Duque de Caxias e, juntamente com os alunos, foram planejadas as ações futuras para a geração dos dados necessários para o compilamento de informações que poderiam subsidiá-los no processo de escrita do texto final.

3 O livro "Em cada memória, um pedaço da história" pode ser lido em: https:// pt.calameo.com/books/005550780cc4a7795653a. 
Dessa forma, a primeira providência foi a de convidar um professor da cidade que havia escrito a sua dissertação sobre as festas escolares do Grupo. Para esse evento, os alunos formularam algumas perguntas previamente e realizaram outras durante a conversa.

Registradas as informações fornecidas pelo professor, os alunos traçaram alguns objetivos, pontuando quais seriam os próximos passos para obterem informações mais precisas acerca do Grupo Escolar. Assim, os alunos decidiram entrevistar pessoas que trabalharam ou estudaram no antigo Grupo. Após elaborarem as primeiras questões, eles puderam entrevistar algumas pessoas e, com o auxílio da professora, retextualizaram essas entrevistas em forma de um texto de memórias.

Seguindo a proposta da OLP, foram realizadas dez oficinas com os alunos dentro da temática do concurso, que é O lugar onde vivo. Porém, as informações obtidas por eles nas entrevistas orientadas pelo material não eram relevantes para a escrita do gênero memórias literárias, além de não proporcionarem aos alunos um engajamento, o que era extremamente necessário para o desenvolvimento das atividades. A partir disso, foi proposto aos alunos dar um novo encaminhamento temático às oficinas.

Essa flexibilização e consequente modificação no planejamento do trabalho docente e na postura de professores e alunos evidencia a segunda contribuição do PL e da SD para o ensino de leitura e escrita: a

\section{ressignificação da prática de alunos e professores.}

Nos Projetos de Letramento, essa reconstrução identitária se dá por meio da agência social, de forma que os envolvidos nesses projetos passam a agir na sociedade, atuando de maneira crítica e cidadã. Em outras palavras, passam a atuar como agentes de letramento, isto é, sujeitos cuja atuação é fundamental para o desenvolvimento do Projeto de Letramento, que dão importante contribuição e sem os quais o projeto não aconteceria da mesma forma. Assim, compreendemos que a professora que desenvolveu o PL em análise foi uma importante agente de letramento, conforme defende Kleiman (2006), mas além dela, também consideramos como agentes de letramento os alunos, cujo protagonismo se destaca, e pessoas da comunidade escolar e externas a ela que deram uma relevante contribuição ao PL, tais como outros professores da escola e pessoas mais velhas da comunidade, cujas entrevistas foram fundamentais para a escrita dos textos de memórias literárias e a produção do livro. 
v. 9 (3)

$360-381$

set-dez

2019

De forma semelhante, um reposicionamento identitário também ocorreu na SD em análise, tendo em vista que, devido à flexibilização no olhar e sensibilidade ao perceber a falta de interesse e de engajamento dos alunos nas atividades, foram feitas modificações no planejamento da professora, as quais permitiram que o trabalho tomasse um rumo diferente do proposto pela OLP e tivesse como resultado práticas exitosas.

Assim, o reposicionamento identitário dos envolvidos nas duas propostas e as modificações feitas em relação ao material da olimpíada, tanto no que se refere ao PL quanto à SD, possibilitaram a escrita de diversos gêneros, e não apenas de memórias literárias, gênero focalizado pela OLP. Nessa perspectiva, emerge a terceira contribuição do PL e da SD para o ensino de leitura e escrita: a produção de diferentes gêneros.

No que diz respeito aos gêneros, no Projeto de Letramento, eles não são definidos a priori, como na SD. São as necessidades do projeto que definem os gêneros discursivos a serem produzidos pelos alunos. Dessa forma, uma rede de atividades/gêneros é desenvolvida para que, por meio dela, eles possam atender a demandas sociais. No PL em análise, a rede de gêneros foi composta por: convite para a exposição de objetos antigos, cartazes expostos na exposição, carta de solicitação para marcar uma entrevista, roteiro para as entrevistas, a entrevista em si, textos de memórias literárias e, por fim, o livro de memórias literárias em versões impressa e digital.

A Sequência Didática da olimpíada, por sua vez, preestabelece os gêneros a serem escritos em cada série. No entanto, na SD em análise, o texto de memórias literárias foi focalizado, mas não foi o único a ser escrito pelos alunos, devido às modificações realizadas nessa Sequência Didática. Assim, textos de diversos gêneros foram escritos antes e depois das memórias literárias: entrevista, plano de trabalho e resumo, os quais foram fundamentais para que as memórias atendessem aos critérios do gênero textual e do concurso.

Nesse sentido, considerando as especificidades do gênero, os alunos participantes da SD produziram duas versões do texto de memórias literárias, além dos outros textos mencionados, dentre as quais, devido a uma necessidade de recorte, destacamos uma, que está transcrita no quadro 4. 
Quadro 4 - Texto de memórias literárias - Sequência Didática

Meu nome é Maria do Rosário Bezerra e tenho 89 anos. Eu me lembro que o Grupo Escolar Duque de Caxias era um prédio enorme. Quando a gente ia entrar na escola, sempre tínhamos que cantar o hino nacional e ficar todos em fila. O chão era de madeira e os meus alunos diziam: "Dona Rosarinho, Barrinhos está lá embaixo olhando as calcinhas da gente!". Eu peguei muitos alunos medonhos. Eu trabalhava no $1^{\circ}$ ano, aí a diretora, que era Lucia Ferreira, me transferiu para o $2^{\circ}$ ano. No dia das matrículas, eu ficava sentada e a diretora lá, fazendo as matrículas, e eu escutava as pessoas dizendo: "vocês 'tudim' vão para Maria do Rosário? E os outros professores do $2^{\circ}$ ano vão ficar com quem?". As mães dos alunos gostavam demais de mim, elas queriam que os filhos delas ficassem comigo. Eu era boa professora e as alunas 'tudim' gostava de mim!

Eu me lembro de algumas pessoas que estudaram no Grupo Escolar Duque de Caxias, como Barrinhos, Aldo Seixas, Valdete, como o povo chamava. Eu era professora por vocação mesmo. Tinha ano que tinha período de afastamento e eu não quis sair da sala de aula. Eu ainda lembro como se fosse hoje quando um senhor chegou na sala e disse: "Maria do Rosário Barros está aposentada". Minhas amigas fizeram uma festa de despedida.

Fonte: Medeiros (2015).

O texto do quadro 4 evidencia as memórias de uma antiga professora em relação ao tempo em que lecionou na escola e que se identificava com a profissão, conforme mostra o trecho "Eu era professora por vocação mesmo". Além disso, ela era bastante querida pelos alunos, pelos pais e colegas de trabalho, como vemos nos trechos "[...] eu escutava as pessoas dizendo: 'vocês 'tudim' vão para Maria do Rosário? E os outros professores do $2^{\circ}$ ano vão ficar com quem?'"; "As mães dos alunos gostavam demais de mim, elas queriam que os filhos delas ficassem comigo" e "Eu ainda lembro como se fosse hoje quando um senhor chegou na sala e disse: 'Maria do Rosário Barros está aposentada'. Minhas amigas fizeram uma festa de despedida".

Dessa forma, mesmo o texto apresentando algumas marcas de oralidade resultantes da entrevista oral, os alunos conseguiram, a partir da retextualização da entrevista, produzir memórias literárias. Além disso, por meio dessas memórias, os alunos tornaram conhecida aos leitores da comunidade escolar a história dessa antiga professora da escola em que estudam, resgatando memórias de profissionais que fazem parte da história da escola e, com isso, modificando a maneira como eles veem a própria escola, valorizando-a ainda mais. Com efeito, a partir das adaptações feitas na SD e da produção de diferentes gêneros, o objetivo de produzir textos de memórias literárias foi alcançado. Isso evidencia a importância que tiveram, tanto na Sequência Didática quanto no Projeto de Letramento, os outros gêneros produzidos. 
v. 9 (3) $360-381$ set-dez 2019

\section{Considerações finais}

A análise que propusemos neste artigo pretendeu delinear aspectos advindos do trabalho com modelos didáticos distintos: Sequências Didáticas e Projetos de Letramento. Dessa forma, além de apontar distinções teóricas e metodológicas das duas propostas, buscamos evidenciar, por meio da análise de um recorte de dados de duas pesquisas de intervenção do Mestrado Profissional em Letras - ProfLetras, contribuições do PL e da SD para o ensino de leitura e escrita: escrita como prática social, ressignificação da prática de alunos e professores, e produção de diferentes gêneros.

Observamos que, mesmo tendo em comum como ponto de partida o interesse em participar de um concurso nacional de escrita, o PL e a SD em análise tomaram rumos diferentes em relação às orientações dadas pelo material da olimpíada. Na SD, isso ocorreu porque o material da OLP não foi suficiente para se atingirem os objetivos propostos relativos à escrita do gênero memórias literárias. Esse distanciamento se intensificou ainda mais no PL, por se tratar de uma perspectiva situada, cujas atividades a serem desenvolvidas emergem das necessidades do projeto, e não de um material didático. No entanto, isso não implica afirmar que não se pode utilizar o modelo didático advindo dos Projetos de Letramento em outras escolas ou situações. Significa que, a cada novo projeto, os participantes poderão refletir sobre um problema a ser resolvido (na escola, na comunidade); em seguida, irão definir, no decorrer do projeto, como se desenvolverá sua rede de atividades e quais gêneros precisarão ser lidos e produzidos pelos participantes para poderem, por meio deles, agir na sociedade.

Assim, os materiais didáticos disponibilizados pela Olimpíada de Língua Portuguesa constituem um importante apoio ao professor de língua materna, mas não devem ser os únicos a serem utilizados. $\mathrm{O}$ professor precisa, então, ter flexibilidade, sensibilidade e engajamento para que possa perceber se seu planejamento está atingindo os objetivos pretendidos e, se não, ter a capacidade de modificá-lo, a partir de outras atividades e da produção de novos gêneros.

\section{Referências}

ARAÚJO, Denise Lino de. o que é (e como faz) sequência didática? Fortaleza: Entrepalavras, ano 3, v.3, n.1, p. 322-334, jan/jul, 2013.

BAKHTIN, Mikhail. Estética da criação verbal. São Paulo: Editora WMF Martins Fontes, 1992. 
CLARA, Regina A.; ALTENFELDER, Anna Helena; ALMEIDA, Neide. Se bem me lembro...: caderno do professor: orientação para a produção de textos. São Paulo: Cenpec, 2002. (Coleção da Olimpíada).

DOLZ, Joaquim; SCHNEUWLY, Bernard. Gêneros orais e escritos na escola. Campinas, SP: Mercado de Letras, 2004.

FERNANDES, Francisca Vaneíse Andrade. Olimpíada de Língua Portuguesa: ressignificação de práticas de leitura e escrita. 135 f. Dissertação (Mestrado Profissional) - Centro de Ciências Humanas, Letras e Artes, Programa de Mestrado Profissional em Letras, Universidade Federal do Rio Grande do Norte, Natal, 2015.

KLEIMAN, Angela B. (Org.). Os significados do letramento: uma perspectiva sobre a prática social da escrita. Campinas, SP: Mercado de Letras, 1995.

KLEIMAN, Angela B. O processo de aculturação pela escrita: ensino da forma ou aprendizagem da função? In: .SIGNORINI, Inês. $\mathbf{0}$ ensino e a formação do professor: alfabetização de jovens e adultos. Porto Alegre: Artmed, 2000. p. 223-243.

KLEIMAN, Angela B. Preciso "ensinar" o letramento?: Não basta ensinar a ler e a escrever? Campinas, SP: Cefiel/IEL/Unicamp, 2005.

KLEIMAN, Angela B. Processos identitários na formação profissional: o professor como agente de letramento. In: CORRÊA, Manoel; BOCH, Françoise. (Orgs.). Ensino de língua: representação e letramento. Campinas, SP: Mercado de Letras, 2006. p. 75-91.

MEDEIROS, Priscila do Vale Silva. Escritas da memória: fomento à leitura e à escrita nas (re)construções identitárias com o gênero memórias literárias. 160 f. Dissertação (Mestrado em Letras- PROFLETRAS) - Universidade do Estado do Rio Grande do Norte, Assú, RN, 2015.

MOITA LOPES, Luiz Paulo da. (Org.). Por uma linguística aplicada indisciplinar. São Paulo: Parábola Editorial, 2006.

OLIVEIRA, Maria do S.; TINOCO, Glícia A.; SANTOS, Ivoneide B. de A. Projetos de letramento e formação de professores de língua materna. Natal: EDUFRN, 2011.

TINOCO, Glícia A. Projetos de letramento: ação e formação de professores de língua materna. 2008. 254 f. Tese (Doutorado em Linguística Aplicada) - Instituto de Estudos da Linguagem, Universidade Estadual de Campinas, Campinas, SP, 2008. 